\title{
Transdural approach to resection of retro-odontoid cysts in elderly patients: report of 3 cases
}

\author{
Karthik Madhavan, MD, Lee Onn Chieng, MD, Brandon G. Gaynor, MD, and Allan D. Levi, MD, PhD \\ Department of Neurological Surgery and Miami Project to Cure Paralysis, University of Miami Miller School of Medicine, \\ Miami, Florida
}

Retro-odontoid cysts that arise from the tectorial membrane are uncommon lesions that can occur in elderly patients. They arise secondary to degenerative changes, including calcium pyrophosphate deposition within the ligaments. Surgical treatment is indicated when these lesions result in intractable pain, instability, and/or myelopathy. Several surgical techniques to treat this condition exist, but the optimal approach in elderly patients with comorbidities remains controversial. Here, the authors present a case series of 3 patients who underwent successful resection of a retro-odontoid lesion performed through a transdural approach.

The patients were 70,81 , and 74 years old and presented with symptoms of cervical myelopathy. In consideration of their advanced age and the location of their lesion, resection via a posterior approach was considered. A 1- to 2-cm suboccipital craniectomy and C-1 and partial C-2 laminectomy were performed. These lesions could not be accessed via an extradural posterolateral approach, and so a transdural approach was performed. In the first 2 patients, a preexisting deformity prompted an instrumented fusion. In the third patient, only a lesion resection was performed. In each case, the dural opening was made using a paramedian ipsilateral-sided incision, and the lesion was resected through an incision in the anterior dura mater. Only the posterior dura was closed primarily. MR imaging evidence of excellent spinal cord decompression was evident in follow-up examinations.

Transdural resection of retro-odontoid cysts is a viable option for treating asymmetrical ventral extradural cysts. Results from this case series suggest that such an approach is safe and feasible and can provide an alternative to open or endoscopic anterior transpharyngeal approaches.

https://thejns.org/doi/abs/10.3171/2017.6.SPINE17429

KEY WORDS transdural; retro-odontoid; elderly; surgical technique; cervical

$\mathrm{T}$ HE atlantoaxial joint represents an intricately balanced bone-ligament complex. Calcium pyrophosphate deposition (CPPD) or pseudogout in the upper cervical spine was described initially by Menezes and colleagues. ${ }^{15,57}$ These benign cystic lesions are located in the retro-odontoid and peri-odontoid areas and are composed of fibrocartilaginous debris. Symptomatic lesions require resection, and several surgical options are often available, including those performed through an anterior transoral/ endoscopic transnasal, far-lateral, or posterior extradural approach. There remains no consensus regarding the optimal approach, because each approach has its own merits and risks. ${ }^{8}$ In the recent past, transdural approaches for the removal of paracentral disc herniation in the subaxial cervical and thoracic spine have been described. $.^{18,39,51} \mathrm{Fu}-$ jiwara et al. ${ }^{19}$ first described the transdural resection of a retro-odontoid fibrocartilaginous lesion in a 66-year-old patient. Here, we present 3 elderly patients with multiple medical comorbidities who underwent surgery performed through a transdural approach to treat their symptomatic retro-odontoid cyst, and we describe the surgical approach used and details on intermediate follow-up for each patient.

\section{Case Reports}

A detailed retrospective chart review of 3 consecutive 


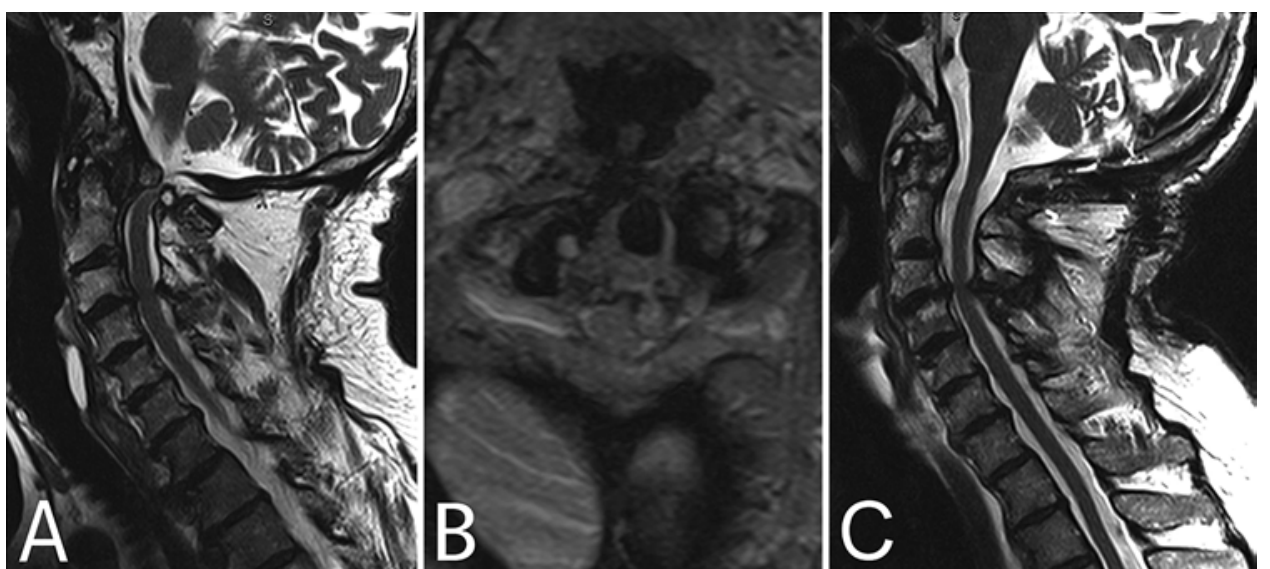

FIG. 1. Sagittal (A) and axial (B) T2-weighted MR images show a retro-odontoid lesion with mixed density and severe left-sided compression of the spinal cord; the cord is being pushed to the right side, as shown in the axial MR image. Sagittal T2-weighted MR image (C) of the cervical spine showing decompression of the ventral spinal cord.

patients who underwent transdural resection of a retroodontoid CPPD mass was conducted. We also carried out a systematic review of surgical management for retroodontoid pseudotumors. We performed a PubMed database search to identify English-language articles published between 1990 and 2016 that contained phrases to describe the pathology involved ("retro-odontoid pseudotumor," "CPPD," and "calcium pyrophosphate deposition") and the surgical approach used ("transdural," "transoral," "laminectomy," "fixation," and "fusion"). Included were case reports, case series, retrospective studies, and prospective reports that discussed the surgical management of retro-odontoid pseudotumors. We excluded all cases of rheumatoid arthritis or any other inflammatory pathology.

Case 1

An 81-year-old man presented with an 8-week history of pain in the neck and upper extremities bilaterally. He also noted dexterity issues, including difficulty in buttoning and tying his shoelaces. Motor examination revealed Grade 5/5 strength in all major muscle groups in his upper and lower extremities and some atrophy in his thenar, interossei, and first dorsal interosseous muscles bilaterally. His neck posture exhibited marked forward kyphosis, particularly when sitting and walking. Cervical MRI (Fig. 1A and B) revealed advanced arthritic changes at the cervicomedullary junction with severe spinal canal narrowing from a left-sided retro-odontoid cyst. The severe narrowing had resulted in myelomalacia of the spinal cord. Some stenosis in the subaxial spine was noted, but no significant compression was shown on the axial T2-weighted images.

The patient underwent surgery, and an attempt was made to approach the lesion extradurally with reversedangle curettes. Intraoperative ultrasound revealed no change in the size of the ventral cystic lesion or the degree of spinal cord compression. Hence, a decision was made intraoperatively to perform a transdural resection of the lesion because of the patient's preexisting kyphotic deformity and extensive lateral dissection.

Histopathological examination revealed fragments of degenerated annulus fibrosus with evidence of prolapse, amorphous debris, histiocytes, and CPPD. An immediate postoperative neurological examination revealed no changes, and the patient was discharged to home uneventfully after 2 days. Three months after surgery, MRI revealed no evidence of pseudotumor recurrence (Fig. 1C). At the 13-month follow-up visit, the patient reported improvement in his numbness and had intact strength and sensation throughout his upper and lower extremities.

\section{Case 2}

A 70-year-old man presented with longstanding occipital pain. Although a retro-odontoid cyst was noted on MRI of his cervical spine 4 years earlier, he was followed up with serial imaging until he was symptomatic with worsening gait, recurrent falls, loss of balance, bladder incontinence, and worsening pain in the occipital region. The patient had a history of pulmonary embolism and longterm anticoagulation treatment, hypertension, asthma, and narrow-angle glaucoma.

An examination revealed full strength in all extremities, mild pronator drift on the right, a shuffling gait, $2-3$ beats of clonus on his right foot, and positive Romberg sign. A CT scan revealed extensive degenerative changes with a kyphotic cervical spine and a relative fusion of vertebral bodies from C-3 through C-7. MRI of his cervical spine revealed evidence of a large right-sided intraspinal partially cystic lesion arising from the tectorial membrane (Fig. 2A and B). It was noted to be compressing his spinal cord severely and shifting it to the left.

After the patient received orotracheal intubation and was positioned prone on a 4-poster frame, the patient's head was pinned using a Mayfield clamp. Once his head was secured with the clamp attached to the bed, the patient was shaved in the suboccipital area, prepped, and draped. A midline incision was made from inion to $\mathrm{C}-3$, and dissection was performed through the fascia to the lamina. We proceeded with a small $1-$ to $2-\mathrm{cm}$ posterior fossa craniectomy using a high-speed pneumatic drill (Medtronic, Inc.). The C-1 lamina was separated from the soft tissue rostral to it, and care was taken not to injure the vertebral artery. Laminectomy of $\mathrm{C}-1$ and the rostral portion of $\mathrm{C}-2$ 

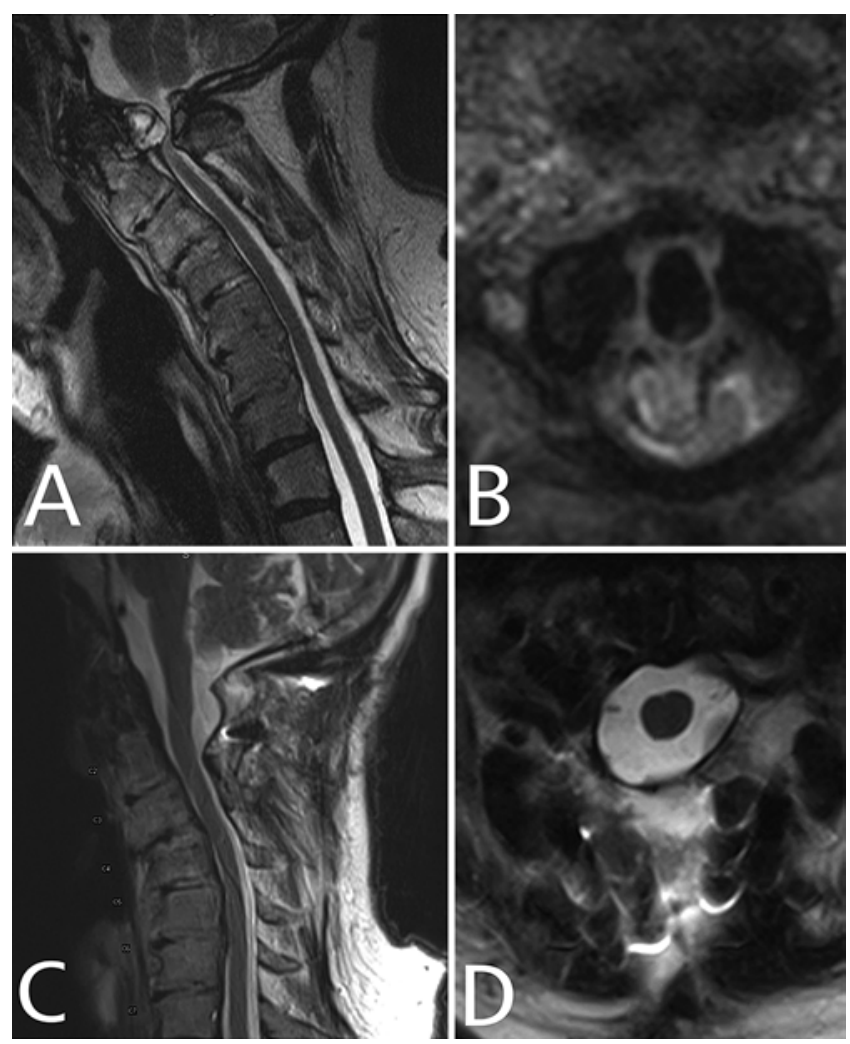

FIG. 2. Sagittal (A) and axial (B) T2-weighted MR images of a retroodontoid lesion showing the cystic nature of the lesion with severe cord compression. The spinal cord is being pushed to the left, as shown in the axial image. Sagittal T2-weighted MR image (C) of the cervical spine showing decompression of the spinal cord at the C1-2 level. Stable kyphosis can be seen in the subaxial cervical spine. Axial T2-weighted MR image (D) of the cervical spine showing excellent decompression of the spinal cord. was performed, and the bone was preserved for later use as autograft for fusion.

We then brought in the operative microscope, and under direct visualization, a paramedian incision was made with an 11-0 blade. We placed 5-0 Prolene retention stitches in the dura mater to elevate it. We identified the right $\mathrm{C}-1$ and C-2 dorsal rootlets, spinal accessory nerve, dentate ligament, and the ventral cystic structure that was causing cord compression (Fig. 3A and B). Then, arachnoid membranes were mobilized, the 11th nerve was mobilized laterally, and the dentate ligament was sectioned. A portion of the dorsal C-2 rootlets was sectioned. The cyst was ventral and extradural in location. A linear incision in the ventral dural and adherent cyst wall was made using an 11-0 blade, and copious yellow-brownish material was drained. We removed additional necrotic cartilaginous material with biopsy forceps and pituitary rongeurs (Video 1).

VIDEO 1. After a paramedian durotomy and placement of tenting sutures, the arachnoid membrane is incised with a No. 11 blade. Microdissection is used to release the arachnoid from the nerve roots, cyst, and spinal cord. The cyst is entered sharply with the No. 11 blade, and liquid cyst contents are spontaneously expressed.

The C-2 nerve rootlets are divided to facilitate removal of the mass. Fibrocartilaginous contents are removed in a piecemeal fashion using pituitary rongeurs, curettes, scissors, and Rhoton microdissectors. The remaining capsule is trimmed with bipolar cautery and scissors. Copyright Allan D. Levi. Published with permission. Click here to view.

Once decompression was satisfactory, edges of the capsule were cauterized with bipolar cautery to shrink them, and the subarachnoid space was irrigated copiously. We closed the dorsal dura with a running 5-0 Prolene stitch and a DuraGen (Integra) graft. We did not feel the need to perform a primary closure of the anterior dura because of its dense adhesion to the posterior wall of the odontoid process.
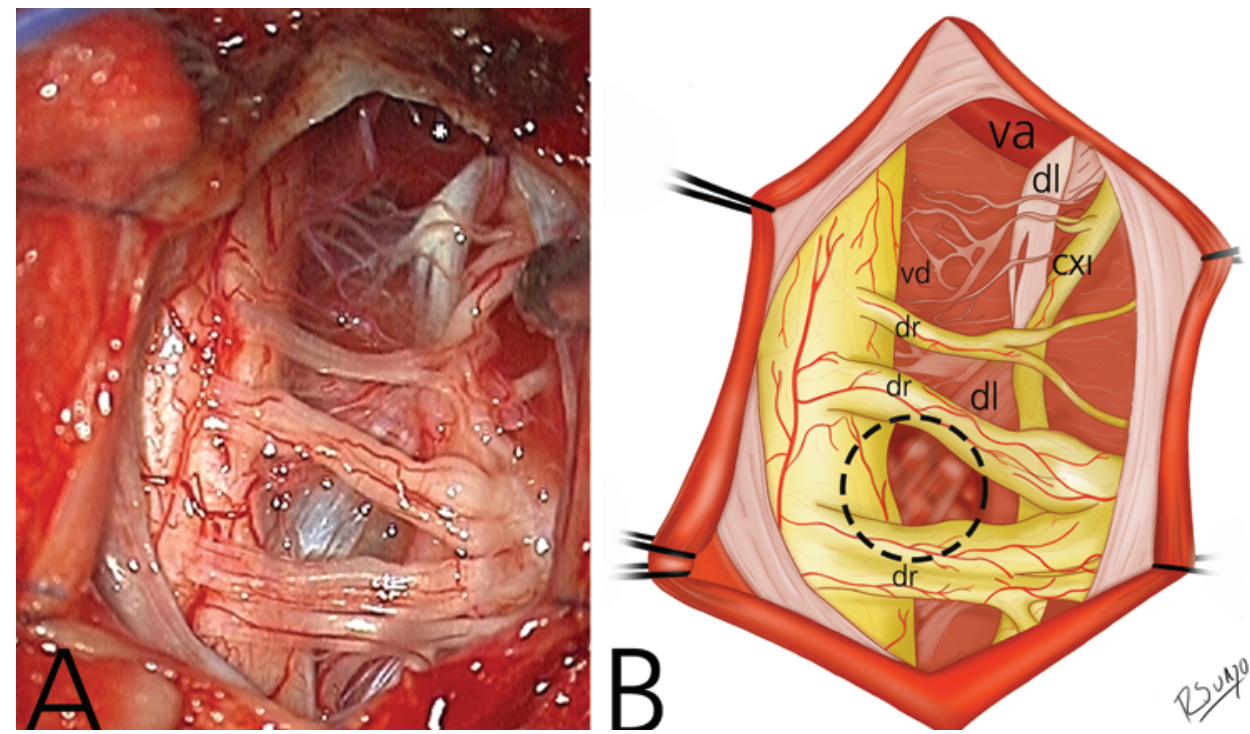

FIG. 3. Intraoperative image (A) and artist's rendition (B) of the appearance of a retro-odontoid cyst at the cervicomedullary junction. Ventral cord compression from the cyst (dashed circle), which is covered by the ventral dura (vd), can be seen, as can the dentate ligament $(\mathrm{dl})$, dorsal rootlets of $\mathrm{C}-1$ and $\mathrm{C}-2(\mathrm{dr})$, cranial nerve XI (CXI), and the intradural segment of the vertebral artery (va). Copyright University of Miami Miller Center. Published with permission. 

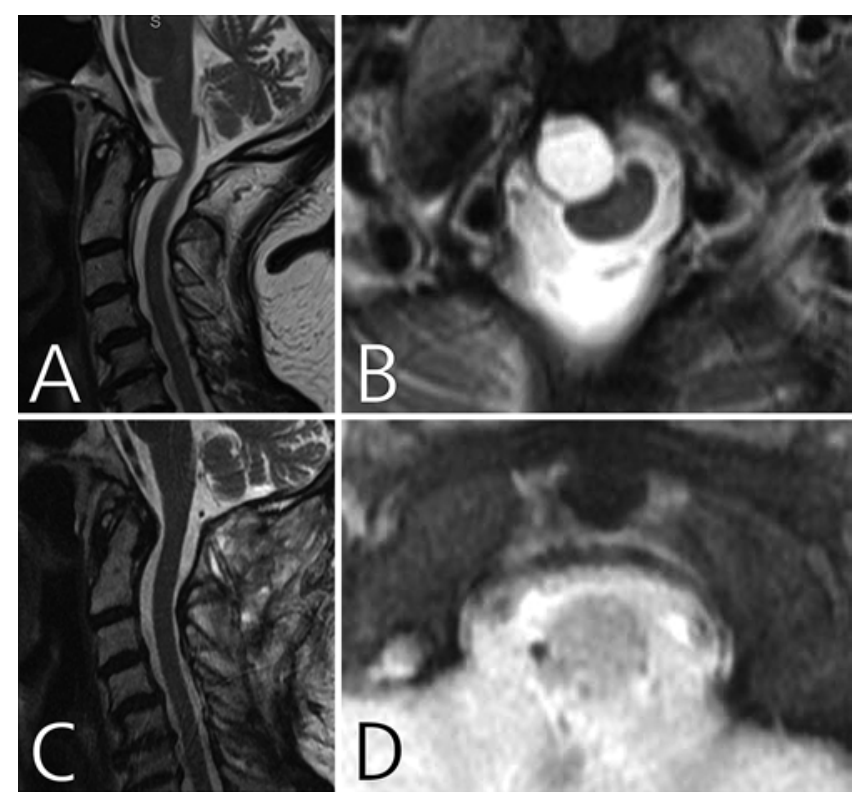

FIG. 4. Sagittal (A) and axial (B) T2-weighted MR images of a retroodontoid lesion showing the cystic nature of the lesion and severe cord compression. The spinal cord is being pushed to the left, as shown in the axial image. Sagittal (C) and axial (D) T2-weighted MR images showing excellent decompression of the spinal cord 3 months after surgery. The previously seen pseudomeningocele was treated successfully with revision surgery.

Using fluoroscopic imaging, an occipitocervical 3-level fusion with allograft and bone morphogenetic protein (2.1 $\mathrm{mg}$ ) was performed.

After surgery, the strength of the patient's extremities remained intact, and he was subsequently transferred to a monitored floor for overnight observation. He had a brief episode of delirium that resolved after we reduced his narcotic medication intake. The head of his bed was elevated to $30^{\circ}$ at all times, and he was discharged 3 days after surgery. At the 1-month follow-up visit, we found that his wound had healed well, and his symptoms, including balance, had improved significantly. Postoperative MRI revealed resolution of ventral compression from the ventral cyst (Fig. 2C and D). At the time of this writing (19 months after surgery), the patient had not experienced symptom recurrence.

\section{Case 3}

A 74-year-old woman presented with a 1-year history of neck pain and radiation to the back of the neck, which was worse on the right side. She obtained symptomatic relief from an epidural steroid injection. However, when the pain recurred after 2 injections, MRI was recommended; it revealed a retro-odontoid cyst on the right side with compression of the spinal cord. Repeat imaging revealed an increase in the size of the cyst (Fig. 4A and B). Her upper-extremity motor examination revealed Grade 5/5 strength in all muscle groups, Grade 4/5 left biceps only and triceps bilaterally. In her lower extremities, she had full strength, except Grade 4+/5 bilaterally in the extensor hallucis longus and Grade 5-/5 in the gastrocnemius; her gait was normal. She had limited range of motion in exten- sion and lateral rotation. She had normal reflexes throughout and absent reflexes in both ankles.

The patient underwent a small posterior fossa craniectomy and a limited C-1 laminectomy, intradural exploration, and resection of the ventral cyst. No fusion was performed in this patient because no preexisting deformity or instability was noted. The patient began ambulating on Postoperative Day 1. She was in the hospital for 4 days after surgery and then was discharged to home. At her 2-week follow-up visit, we found that the surgical site was healing well and the patient was experiencing minimal pain. According to the neurological examination, she was stable and had no posterior fossa headaches. The patient was followed up once again 3 months after surgery. MRI revealed complete resolution of the ventral tectorial cyst but also a sizeable dorsally located pseudomeningocele. She underwent surgery for primary repair of a small central opening at the previous suture line in the dorsal dura. The opening was repaired directly with 5-0 Prolene sutures, a DuraGen graft, and placement of a lumbar drain for 2 days. She stayed in the hospital for 3 days and then was discharged home. Four months after surgery, the patient underwent MRI (Fig. 4C and D), which revealed resolution of the preoperative tectorial cyst, postoperative pseudomeningocele, and preoperative symptoms. Seven months after surgery, she remained asymptomatic.

\section{Systematic Review}

Our PubMed search yielded 356 articles; after we applied our inclusion and exclusion criteria, we narrowed the results to 9 articles. A total of 54 patients were included in the studies. Only 31 of the 54 patients had CPPD confirmed postoperatively. Clinical outcomes and complications are listed in Table 1. Thirty-six patients underwent surgery performed through a transoral approach, and 92\% of them experienced resolution of their symptoms; $67 \%$ of them underwent concurrent posterior fusion. Nonetheless, 3 patients (8\%) experienced postoperative respiratory-related complications. Of those who underwent surgery performed through a posterior-only approach, all patients experienced improvement of symptoms and low complication rates. One of the patients in the posterior-only-approach cohort experienced a CSF leak.

\section{Discussion}

Intradural spinal surgery was reported first in 1910 by Taylor, ${ }^{52}$ who used a unilateral hemilaminectomy and resection of a ventral intradural lesion. In 1928, Stookey ${ }^{47}$ extended Taylor's approach to transdural resection of ventral extradural "chondroma," which was noted eventually to be disc herniations. ${ }^{1,14,42,46}$ After sectioning the dentate ligament and mobilizing the spinal cord, he incised the anterior dura to reach the ventral extradural disc. ${ }^{47}$ Although, these surgeries led to successful resection of herniated discs, the outcomes were poor; patients had difficulty walking and poor coordination months after surgery.,14 The posterior approach for discectomy declined in popularity as Cloward ${ }^{12}$ and Smith and Robinson ${ }^{45}$ independently pioneered the anterior approach in $1958 .^{18,29}$ Some resurgence of interest in transdural approaches has occurred more 
TABLE 1. Systematic review of age, approach, outcome, and treatment complications in patients with retro-odontoid cysts

\begin{tabular}{|c|c|c|c|c|c|c|}
\hline $\begin{array}{l}\text { Authors } \\
\& \text { Year }\end{array}$ & $\begin{array}{l}\text { No. } \\
\text { of Pts }\end{array}$ & $\begin{array}{l}\text { Mean Age } \\
\text { (range) }\end{array}$ & Approach & Outcome & Complication(s) & $\begin{array}{l}\text { FU (range) } \\
\text { in Mos }\end{array}$ \\
\hline $\begin{array}{l}\text { Zünkeler et } \\
\quad \text { al., } 1996^{*}\end{array}$ & 7 & $75.6(68-84)$ & $\begin{array}{l}\text { Transoral-transpalatopha- } \\
\text { ryngeal; } 6 \text { pts required } \\
\text { posterior fusion }\end{array}$ & All improved symptomatically & 1 had pneumonia & NA \\
\hline $\begin{array}{l}\text { Fenoy et al., } \\
2008^{*}\end{array}$ & 21 & $70.3(49-86)$ & $\begin{array}{l}\text { Transoral-transpalatopharyn- } \\
\text { geal; } 16 \text { required concur- } \\
\text { rent posterior fusion }\end{array}$ & $\begin{array}{l}18(86 \%) \text { experienced resolution of } \\
\text { symptoms }\end{array}$ & $\begin{array}{l}1 \text { had postop respira- } \\
\text { tory distress, pneu- } \\
\text { monia, \& palatal } \\
\text { wound dehiscence; } \\
\text { reop was required }\end{array}$ & 15 \\
\hline $\begin{array}{l}\text { Klineberg et } \\
\text { al., } 2014^{*}\end{array}$ & 1 & 83 & Transoral aspiration (MIS) & Neurological improvement & $\begin{array}{l}\text { Postop respiratory } \\
\text { distress necessitat- } \\
\text { ing intubation }\end{array}$ & 6 \\
\hline $\begin{array}{l}\text { Manhas et } \\
\text { al., 2016* }\end{array}$ & 1 & 74 & $\begin{array}{l}\text { C-1 laminectomy \& far-lateral } \\
\text { craniotomy }\end{array}$ & $\begin{array}{l}\text { Improved at } 2 \text { mos but deteriorated } \\
\text { at } 7 \text { mos }\end{array}$ & Recurrence & 7 \\
\hline $\begin{array}{l}\text { Frempong- } \\
\text { Boadu et } \\
\text { al., } 2002^{*}\end{array}$ & $\begin{array}{l}7 \text { (only } 1 \\
\text { had CPPD) }\end{array}$ & $49.3(23-72)$ & Endoscopic transoral & $\begin{array}{l}\text { All had either a stable or improved } \\
\text { neurological status }\end{array}$ & $\begin{array}{l}\text { None, but } 1 \text { died as a } \\
\text { result of periop Ml }\end{array}$ & 6.16 \\
\hline $\begin{array}{l}\text { Kakutani et } \\
\text { al., 2013† }\end{array}$ & 7 & $75.6(64-87)$ & $\begin{array}{l}\text { C-1 laminectomy w/ or w/o } \\
\text { laminoplasty }\end{array}$ & $\begin{array}{l}\text { All had improved myelopathy \& } \\
\text { reduced pseudotumor size }\end{array}$ & None & 12 \\
\hline $\begin{array}{l}\text { Barbagallo et } \\
\text { al., 2013† }\end{array}$ & 5 & $64.8(55-76)$ & $\begin{array}{l}\text { All pts underwent } \mathrm{C} 1-2 \text { fixa- } \\
\text { tion; } 2 \text { pts underwent } \mathrm{OC} \\
\text { fusion }\end{array}$ & $\begin{array}{l}\text { All improved except for } 1 \text { who died } \\
\text { of an unrelated cause; complete } \\
\text { reduction of cyst size in } 2\end{array}$ & None & $32(22-45)$ \\
\hline $\begin{array}{l}\text { Suetsuna et } \\
\text { al., 2006† }\end{array}$ & 3 & $72(66-76)$ & $\begin{array}{l}\text { All pts underwent C-1 lamino- } \\
\text { plasty w/o fusion }\end{array}$ & $\begin{array}{l}\text { All had improved JOA score \& neck } \\
\text { pain; complete reduction of pseu- } \\
\text { dotumor size in 2; partial reduction } \\
\text { of pseudotumor size in } 1\end{array}$ & None & NA \\
\hline $\begin{array}{l}\text { Shah et al., } \\
\text { 2016† }\end{array}$ & 2 & $29(16-42)$ & C1-2 fusion only & $\begin{array}{l}\text { Both improved symptomatically \& had } \\
\text { complete regression of pseudotu- } \\
\text { mor on immediate postop imaging }\end{array}$ & None & 24 \\
\hline $\begin{array}{l}\text { Current } \\
\text { cases }\end{array}$ & 3 & $78.3(70-81)$ & $\begin{array}{l}\text { Posterior transdural w/ OC } \\
\quad \text { fusion (in } 2 \text { pts) }\end{array}$ & All improved symptomatically & CSF leak & 12 \\
\hline
\end{tabular}

FU = follow-up; JOA = Japanese Orthopaedic Association; MI = myocardial infarction; MIS = minimally invasive surgery; $\mathrm{NA}$ = not available; OC = occipitocervical; pts = patients.

* CPPD only.

$†$ Nonspecified retro-odontoid pseudotumors.

recently. Fujimoto et al. ${ }^{18,51}$ presented the cases of 30 patients with myelopathy that resulted from disc herniation between C-3 and C-7. The advantage conferred by such an approach is the prevention of fusion in central disc herniations. No recurrence was found on follow-up. Fujiwara et al. ${ }^{19}$ extended this procedure to resection of a retro-odontoid pseudotumor transdurally via a C-1 laminectomy. They did not perform a suboccipital craniotomy. No fusion was performed, because no signs of instability were noted on the preoperative radiographs. In addition, no recurrence was noted in the 1 year of follow-up.

Rheumatoid arthritis, ${ }^{27,34}$ trauma, ${ }^{24}$ and hemodialysis ${ }^{28,41}$ have been associated with nonneoplastic lesions that arise from around the odontoid process and result in thickening of the transverse ligaments that exerts mass effect on the spinal cord. They are distinct from the retro-odontoid cysts

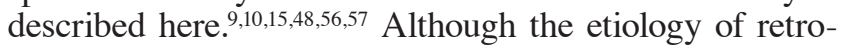
odontoid cysts remains controversial, several theories, including pseudogout with CPPD deposition, chronic subluxation, and instability, have been proposed. ${ }^{13,22,31,49}$ These lesions are managed predominantly through a combined anterior-posterior approach or far-lateral approach, all of which have their own set of risks for complications. ${ }^{21,32}$ Any anterior approach that entails a transnasal or transoral/transpharyngeal approach with resection of the odontoid process to access the lesion in elderly patients has been noted to result in a high rate of morbidity, including infection, spinal fluid leak, longer operative time, and frequent need for posterior instrumented stabilization., ${ }^{2,11,26}$ Based on a review of the literature, the incidence of postoperative sepsis, cervical infection, or respiratory or cardiac complications was reported in up to $8.3 \%$ of patients. ${ }^{8,23}$ The literature discussed here pertains predominantly to patients with rheumatoid arthritis.

Goel and colleagues ${ }^{44}$ observed in their patients that retro-odontoid pseudotumors resulted from buckling of the tectorial membrane caused by chronic instability from trauma, and they managed these cases with distraction and fusion. Radiological evidence of instability was found on the scans of these patients. Barbagallo et al. ${ }^{3}$ reported 
noninflammatory pseudotumors that responded to posterior stabilization only. Manhas et al..$^{38}$ observed that 1 of their patients developed recurrence of a pseudogout cyst 7 months after an initial far-lateral craniotomy and C-1 laminectomy, which indicates likely chronic instability as the etiology. Instrumentation was performed to address deformity and prevent recurrence from chronic instability, because the etiology of the lesion was still debatable. Although we attempted an extradural lateral approach, extensive adhesion of the anterior dura to the back of the vertebral body and constant bleeding from epidural veins limit this approach..$^{19}$ Lateral approaches for treating lesions located between the lower clivus and upper second cervical vertebrae with lateral extension to the jugular tubercle have been described. ${ }^{20,30}$ Approach-related morbidities have included cranial nerve IX and X (44\%) and XII (33\%) palsies, with complete recovery in $66 \%$ of patients, ${ }^{50}$ hemiparesis, ${ }^{36} \mathrm{CSF}$ leak in $16 \%-20 \%$ of patients, ${ }^{4,40,55}$ and instability (after removal of greater than $50 \%$ of the occipital condyle).$^{53} \mathrm{~A}$ meta-analysis revealed significant improvement in overall outcome in $80 \%$ of patients, whereas $9 \%$ worsened postoperatively and $6.7 \%$ remained stable; ${ }^{36}$ worsening was correlated with size of the tumor. ${ }^{43}$ Mortality rates of $0 \%-3 \%$ have been reported..$^{5,6,33,43,50}$ Other complications that were small in number but significant included air embolism, postoperative epidural hematoma, wound infection, and vertebral artery injury. ${ }^{16}$

In this paper, we present a case series of 3 elderly patients with progressive myelopathy secondary to a retroodontoid cyst. Elderly patients deteriorate rather quickly from deconditioning if they are immobilized because of progressive and untreated cervical myelopathy. ${ }^{37,54}$ In addition, from our institutional experience and that described in the literature, we have noted high complication rates in elderly patients who undergo a transnasal endoscopic or transoral procedure. ${ }^{25}$ To date, Menezes and colleagues ${ }^{15}$ have published the largest case series of surgical experience with patients with retro-odontoid pseudogout. They used a transoral-transpharyngeal approach for direct access to all ventrally located masses. Most of these ventral approaches were followed by posterior segmental fusion immediately afterward or in a delayed fashion (1 week to 1 year). Of 19 patients, 3 had not improved by the most recent follow-up. One patient experienced palatal wound dehiscence that required reoperation and tracheostomy. The invasive nature of surgery performed through such a transpharyngeal approach increases the risk of surgical wound contamination by normal flora. A minimal transoral approach has emerged as a promising alternative, because it required less dissection. Klineberg et al..$^{35}$ used a cannula for direct aspiration of the cyst in an 83-year-old woman, and her postoperative course was complicated by respiratory distress that necessitated reintubation. Nonetheless, the patient had achieved complete resolution of the cyst by the 6-month follow-up visit. Fessler and colleagues ${ }^{17}$ were among the first surgeons to use an endoscopically assisted transoral-transpharyngeal approach to resect a pseudogout granulation mass in a 58-year-old man. Despite the minimal surgical exposure, posterior fusion was performed separately to achieve resolution of symptoms without any major postoperative complication in the short-term follow-up period.
Despite the advanced age of our patients (70, 81, and 74 years) and multiple medical comorbidities, they tolerated surgery well without any immediate postoperative complications. We would not recommend this approach if the spinal cord completely drapes the ventral lesion and no surgical window to the cyst wall exists.

\section{Conclusions}

In this small case series, we focused on the technical aspects of resection and outcomes in patients with a retroodontoid cyst. We believe that this approach can obviate some of the morbidities related to ventral approaches in elderly patients and should be considered part of the surgical armamentarium for treating asymmetrical ventral lesions of the upper cervical spinal cord.

\section{References}

1. Andrae R: Über Knorpelknötchen am hinteren Ende der Wirbelbandscheiben im Bereich des Spinalkanals. Beitr Pathol Anat 82:464-474, 1929

2. Assaker R, Louis E, Boutry N, Bera-Louville A, Paul Lejeune J: Foramen magnum syndrome secondary to calcium pyrophosphate crystal deposition in the transverse ligament of the atlas. Spine (Phila Pa 1976) 26:1396-1400, 2001

3. Barbagallo GM, Certo F, Visocchi M, Palmucci S, Sciacca G, Albanese V: Disappearance of degenerative, non-inflammatory, retro-odontoid pseudotumor following posterior $\mathrm{C} 1-\mathrm{C} 2$ fixation: case series and review of the literature. Eur Spine J 22 (Suppl 6):S879-S888, 2013

4. Bassiouni H, Ntoukas V, Asgari S, Sandalcioglu EI, Stolke D, Seifert V: Foramen magnum meningiomas: clinical outcome after microsurgical resection via a posterolateral suboccipital retrocondylar approach. Neurosurgery 59:1177-1187, 2006

5. Borba LA, de Oliveira JG, Giudicissi-Filho M, Colli BO: Surgical management of foramen magnum meningiomas. Neurosurg Rev 32:49-60, 2009

6. Bruneau M, George B: Foramen magnum meningiomas: detailed surgical approaches and technical aspects at Lariboisière Hospital and review of the literature. Neurosurg Rev 31:19-33, 2008

7. Bucy PC, Heimburger RF, Oberhill HR: Compression of the cervical spinal cord by herniated intervertebral discs. J Neurosurg 5:471-492, 1948

8. Chieng LO, Madhavan K, Vanni S: Pooled data analysis on anterior versus posterior approach for rheumatoid arthritis at the craniovertebral junction. Neurosurg Focus 38(4):E18, 2015

9. Chikuda H, Seichi A, Takeshita K, Shoda N, Ono T, Matsudaira K, et al: Radiographic analysis of the cervical spine in patients with retro-odontoid pseudotumors. Spine (Phila Pa 1976) 34:E110-E114, 2009

10. Cihanek M, Fuentès S, Metellus P, Pech-Gourg G, Dufour H, Grisoli F: [Disappearance of retro-odontoid pseudotumor after C1-C2 transarticular fixation screw.] Neurochirurgie 54:32-36, 2008 (Fr)

11. Ciricillo SF, Weinstein PR: Foramen magnum syndrome from pseudogout of the atlanto-occipital ligament. Case report. J Neurosurg 71:141-143, 1989

12. Cloward RB: The anterior approach for removal of ruptured cervical disks. J Neurosurg 15:602-617, 1958

13. Crockard HA, Sett P, Geddes JF, Stevens JM, Kendall BE, Pringle JA: Damaged ligaments at the craniocervical junction presenting as an extradural tumour: a differential diagnosis in the elderly. J Neurol Neurosurg Psychiatry 54:817-821, 1991

14. Fager CA: Posterolateral approach to ruptured median and paramedian cervical disk. Surg Neurol 20:443-452, 1983 
15. Fenoy AJ, Menezes AH, Donovan KA, Kralik SF: Calcium pyrophosphate dihydrate crystal deposition in the craniovertebral junction. J Neurosurg Spine 8:22-29, 2008

16. Flores BC, Boudreaux BP, Klinger DR, Mickey BE, Barnett SL: The far-lateral approach for foramen magnum meningiomas. Neurosurg Focus 35(6):E12, 2013

17. Frempong-Boadu AK, Faunce WA, Fessler RG: Endoscopically assisted transoral-transpharyngeal approach to the craniovertebral junction. Neurosurgery 51 (5 Suppl):S60-S66, 2002

18. Fujimoto Y, Baba I, Sumida T, Tanaka N, Oka S, Kawagoe H: Microsurgical transdural discectomy with laminoplasty: New treatment for paracentral and paracentroforaminal cervical disc herniation associated with spinal canal stenosis. Spine (Phila Pa 1976) 27:715-721, 2002

19. Fujiwara Y, Manabe H, Sumida T, Tanaka N, Hamasaki T: Microscopic posterior transdural resection of cervical retroodontoid pseudotumors. J Spinal Disord Tech 28:363-369, 2015

20. George B, Dematons C, Cophignon J: Lateral approach to the anterior portion of the foramen magnum. Application to surgical removal of 14 benign tumors: technical note. Surg Neurol 29:484-490, 1988

21. Goel A: Is it necessary to resect osteophytes in degenerative spondylotic myelopathy? J Craniovertebr Junction Spine 4:1-2, 2013

22. Goel A: Retro-odontoid mass. J Neurosurg Spine 26:269272, 2017 (Letter)

23. Goel A, Dange N: Immediate postoperative regression of retroodontoid pannus after lateral mass reconstruction in a patient with rheumatoid disease of the craniovertebral junction. Case report. J Neurosurg Spine 9:273-276, 2008

24. Goel A, Phalke U, Cacciola F, Muzumdar D: Atlantoaxial instability and retroodontoid mass - two case reports. Neurol Med Chir (Tokyo) 44:603-606, 2004

25. Goldschlager T, Härtl R, Greenfield JP, Anand VK, Schwartz TH: The endoscopic endonasal approach to the odontoid and its impact on early extubation and feeding. J Neurosurg 122:511-518, 2015

26. Griesdale DE Jr, Boyd M, Sahjpaul RL: Pseudogout of the transverse atlantal ligament: an unusual cause of cervical myelopathy. Can J Neurol Sci 31:273-275, 2004

27. Grob D, Würsch R, Grauer W, Sturzenegger J, Dvorak J: Atlantoaxial fusion and retrodental pannus in rheumatoid arthritis. Spine (Phila Pa 1976) 22:1580-1584, 1997

28. Hatakeyama A, Fujinaga H, Togo T, Tamura T, Ozawa K, Shoji T, et al: Remarkable improvement of activity by CAPD in a hemodialysis patient with a pseudotumor of the craniocervical junction. Adv Perit Dial 8:116-119, 1992

29. Heary RF, Madhavan K: The history of spinal deformity. Neurosurgery 63 (3 Suppl):5-15, 2008

30. Heros RC: Lateral suboccipital approach for vertebral and vertebrobasilar artery lesions. J Neurosurg 64:559-562, 1986

31. Jun BY, Yoon KJ, Crockard A: Retro-odontoid pseudotumor in diffuse idiopathic skeletal hyperostosis. Spine (Phila Pa 1976) 27:E266-E270, 2002

32. Kakutani K, Doita M, Yoshikawa M, Okamoto K, Maeno K, Yurube T, et al: C1 laminectomy for retro-odontoid pseudotumor without atlantoaxial subluxation: review of seven consecutive cases. Eur Spine J 22:1119-1126, 2013

33. Kano T, Kawase T, Horiguchi T, Yoshida K: Meningiomas of the ventral foramen magnum and lower clivus: factors influencing surgical morbidity, the extent of tumour resection, and tumour recurrence. Acta Neurochir (Wien) 152:79-86, 2010

34. Kenéz J, Turóczy L, Barsi P, Veres R: Retro-odontoid "ghost" pseudotumours in atlanto-axial instability caused by rheumatoid arthritis. Neuroradiology 35:367-369, 1993

35. Klineberg E, Bui T, Schlenk R, Lieberman I: Retro-odontoid calcium pyrophosphate dehydrate deposition: surgical management and review of the literature. Evid Based Spine Care J 5:63-69, 2014

36. Komotar RJ, Zacharia BE, McGovern RA, Sisti MB, Bruce JN, D'Ambrosio AL: Approaches to anterior and anterolateral foramen magnum lesions: A critical review. J Craniovertebr Junction Spine 1:86-99, 2010

37. Madhavan K, Chieng LO, Foong H, Wang MY: Surgical outcomes of elderly patients with cervical spondylotic myelopathy: a meta-analysis of studies reporting on 2868 patients. Neurosurg Focus 40(6):E13, 2016

38. Manhas A, Kelkar P, Keen J, Rostad S, Delashaw JB: Recurrent craniocervical pseudogout: indications for surgical resection, surveillance imaging, and craniocervical fixation. Cureus 8:e511, 2016

39. Moon SJ, Lee JK, Jang JW, Hur H, Lee JH, Kim SH: The transdural approach for thoracic disc herniations: a technical note. Eur Spine J 19:1206-1211, 2010

40. Pamir MN, Kiliç T, Ozduman K, Türe U: Experience of a single institution treating foramen magnum meningiomas. J Clin Neurosci 11:863-867, 2004

41. Rousselin B, Helenon O, Zingraff J, Delons S, Drueke T, Bardin T, et al: Pseudotumor of the craniocervical junction during long-term hemodialysis. Arthritis Rheum 33:1567-1573, 1990

42. Schmorl G: Über Knorpelknoten an der Hinterfläche der Wirbelbandscheiben. Fortschr Röntgenstr 40:629, 1929

43. Sekhar LN, Wright DC, Richardson R, Monacci W: Petroclival and foramen magnum meningiomas: surgical approaches and pitfalls. J Neurooncol 29:249-259, 1996

44. Shah A, Jain S, Kaswa A, Goel A: Immediate postoperative disappearance of retro-odontoid "pseudotumor." World Neurosurg 91:419-423, 2016

45. Smith GW, Robinson RA: The treatment of certain cervicalspine disorders by anterior removal of the intervertebral disc and interbody fusion. J Bone Joint Surg Am 40-A:607-624, 1958

46. Stookey B: Compression of spinal cord and nerve roots by herniation of the nucleus pulposus in the cervical region. Arch Surg Chicago 40:417-432, 1940

47. Stookey B: Compression of the spinal cord due to ventral extradural cervical chondromas: diagnosis and surgical treatment. Arch NeurPsych:275-291, 1928

48. Suetsuna F, Narita H, Ono A, Ohishi H: Regression of retroodontoid pseudotumors following C-1 laminoplasty. Report of three cases. J Neurosurg Spine 5:455-460, 2006

49. Sze G, Brant-Zawadzki MN, Wilson CR, Norman D, Newton TH: Pseudotumor of the craniovertebral junction associated with chronic subluxation: MR imaging studies. Radiology 161:391-394, 1986

50. Talacchi A, Biroli A, Soda C, Masotto B, Bricolo A: Surgical management of ventral and ventrolateral foramen magnum meningiomas: report on a 64-case series and review of the literature. Neurosurg Rev 35:359-368, 2012

51. Tanaka N, Fujimoto Y, Sumida T, Manabe H, Nakanishi K, Fujiwara Y, et al: Long-term clinical results of microsurgical transdural discectomy with laminoplasty: follow-up results over 10 years. J Neurosurg Spine 18:653-660, 2013

52. Taylor AS: X. Unilateral laminectomy. Ann Surg 51:529_ 533, 1910

53. Vishteh AG, Crawford NR, Melton MS, Spetzler RF, Sonntag VK, Dickman CA: Stability of the craniovertebral junction after unilateral occipital condyle resection: a biomechanical study. J Neurosurg 90 (1 Suppl):91-98, 1999

54. Wang MY, Widi G, Levi AD: The safety profile of lumbar spinal surgery in elderly patients 85 years and older. Neurosurg Focus 39(4):E3, 2015

55. Wu Z, Hao S, Zhang J, Zhang L, Jia G, Tang J, et al: Foramen magnum meningiomas: experiences in 114 patients at a single institute over 15 years. Surg Neurol 72:376-382, 2009 
56. Yoshida K, Hanyu T, Takahashi HE: Progression of rheumatoid arthritis of the cervical spine: radiographic and clinical evaluation. J Orthop Sci 4:399-406, 1999

57. Zünkeler B, Schelper R, Menezes AH: Periodontoid calcium pyrophosphate dihydrate deposition disease: "pseudogout" mass lesions of the craniocervical junction. J Neurosurg 85:803-809, 1996

\section{Disclosures}

Dr. Levi receives a teaching honorarium from the American Association of Neurosurgeons (AANS) and grant support from the Department of Defense.

\section{Author Contributions}

Conception and design: all authors. Acquisition of data: all authors. Analysis and interpretation of data: all authors. Drafting the article: all authors. Critically revising the article: all authors. Reviewed submitted version of manuscript: all authors. Approved the final version of the manuscript on behalf of all authors: Levi. Study supervision: Levi.

\section{Supplemental Information}

Videos

Video 1. https://vimeo.com/229838685.

\section{Correspondence}

Allan D. Levi, Department of Neurological Surgery, University of Miami Miller School of Medicine, Lois Pope Life Center, 1095 NW 14th Terrace (D4-6), Miami, FL 33136. email: alevi@med. miami.edu. 